\title{
Comunidades florestais como indicadores geobotânicos: o caso da mineralização aurífera do Grupo Serra do Itaberaba, Guarulhos, São Paulo
}

\author{
Teodoro Isnard Ribeiro de Almeida ${ }^{1}$, Caetano Juliani ${ }^{2}$, Waldir Mantovani ${ }^{3}$ \& Annabel \\ Pérez-Aguilar ${ }^{4}$
}

\begin{abstract}
Resumo A geobotânica, mesmo sendo possivelmente o primeiro método indireto de prospecção de minérios metálicos, não vem sendo utilizada pela comunidade, sobretudo em florestas tropicais. O principal motivo pode ser a falta de geólogos com conhecimentos de botânica. Há autores que consideram serem as florestas de climas frios e temperados mais adaptadas à técnica pela mais pobre biodiversidade, solos menos espessos e maior interação da vegetação com as rochas encaixantes, deixando as amplas florestas tropicais sem tal abordagem. O objetivo deste trabalho é demonstrar a intensa influência de um processo mineralizante - alteração hidrotermal clorítica - em segmento de Mata Atlântica. São apresentados os resultados de estudo botânico de dois segmentos de floresta atlântica montana crescidos sobre rochas da Formação Morro da Pedra Preta, Grupo Serra do Itaberaba: um sobre rochas meta-básicas e outro sobre rochas metabásicas e metaintermediárias afetadas por um evento de alteração clorítica ao qual estão geneticamente associadas mineralizações de ouro. Observe-se que as metaintermediárias têm composições químicas muito próximas às das rochas básicas. Os dados obtidos em campo evidenciam importante dissimilaridade fisionômica e florística entre as coberturas vegetais, as quais podem ser atribuídas apenas à presença de alteração hidrotermal nas rochas do substrato de uma das parcelas, pois estas são vizinhas e têm iguais parâmetros de altitude, direção e inclinação de encosta e história de sucessão florística. Com este dado, a geobotânica, particularmente associada ao sensoriamento remoto óptico, assunto não tratado neste trabalho, deve ter seu uso seriamente considerado na prospecção mineral e no mapeamento geológico básico em outros biomas com florestas mais preservadas, como na Amazônia.
\end{abstract}

Palavras-chave: geobotânica, alteração hidrotermal, comunidades florestais, Mata Atlântica

Abstract Forest communities as geobotanical indicators: the case of the auriferous mineralization of Serra do Itaberaba Group, Guarulhos, São Paulo. The geobotany was probably the first indirect method of metallic ore exploration. However it is rarely used by the community, especially in tropical forests, probably because of the difficulties to have a geologist with high botanical knowledge. Some authors believe that cold and temperate forests are more adapted to the technique due to its poorer biodiversity, thinner soils and greater vegetation interaction with the bedrock. The objective of this work is to demonstrate the intense influence of a mineralization process - chloritic hydrothermal alteration - on the Mata Atlantic rain forest. We present the results of a botanical study of two segments of mountainous Atlantic forest grown on soils over rocks of Morro da Pedra Preta Formation, Serra do Itaberaba Group: one over metabasic rocks and another over metabasic and meta-intermediate rocks submitted to chloritic alteration, which is genetically associated to gold mineralizations. The meta-intermediate rocks chemical compositions are very near to those of basic rocks. The field data reveals important physiognomic and floristic dissimilarities between the two forests, which can be attributed directly to the presence of hydrothermal alteration, since the studied areas are neighboring and have near identical parameters of altitude, direction and inclination of hillside and history of floristic succession. It is suggested that geobotany, particularly associated with optical remote sensing, which was not discussed in this work, may be considered as an important tool in the mineral exploration and geological mapping in preserved rain forests, as in Amazon.

Keywords: geobotany, hydrothermal alteration, forest communities, Atlantic Tropical Forest

INTRODUÇÃO A identificação de alterações nas coberturas vegetais como indicadoras de minérios metálicos é um aspecto em geral relegado pelos geólogos, decerto por se tratar de uma área de interface entre várias especialidades. Entretanto a geobotânica, ou seja, a utilização da cobertura vegetal como fonte de infor-

1 - Instituto de Geociências, Universidade de São Paulo, São Paulo, SP. E-mail: talmeida@usp.br

2 - Instituto de Geociências, Universidade de São Paulo, São Paulo, SP. E-mail: e-mail:cjuliani@usp.br

3 - Instituto de Biociências, Universidade de São Paulo, São Paulo, SP. E-mail: wmantova@ib.usp.br

4 - Instituto Geológico, SMA, São Paulo, SP. E-mail: annabelp@igeologico.sp.gov.br 
mações geológicas indiretas, é algo intuitivo e tem sido utilizado pela humanidade desde que esta passou a procurar minérios metálicos.

Georgius Agrícola, considerado na cultura ocidental como o criador da geologia, citava em 1556, em De Re Metallica, haver senescência precoce e nanismo de plantas crescidas sobre corpos de minério (Ustin et al., 1999). Assim a geobotânica foi provavelmente o primeiro método indireto de prospecção de minérios metálicos a ser definido. Já no Oriente, Xu \& Ma (2004) afirmam que se usava a técnica na China há mais de 2000 anos, sendo reconhecidas desde então plantas indicadoras de depósitos minerais.

As correlações geobotânicas fazem-se segundo duas grandes vertentes. Uma enfatiza as relações entre plantas específicas e solos, como definido no século XIX, com a criação de termos ainda hoje em uso, tais como plantas halófitas, hidrófitas etc. (Ustin et al., 1999). Neste aspecto a literatura descreve diversas plantas indicadoras, como Becium homblei, Haumaniastrum katangense e Haumaniastrum robertii, associadas a minério de cobre, Combretum decandrum e Miliusa tomentosa, a minério de níquel (Baker \& Brooks, 1988) e Gymnosperma montana, a pegmatitos (Nagaraju \& Karimulla, 2001). A outra vertente contempla variações na estrutura fisionômica e na composição de espécies em solos desenvolvidos sobre mineralizações. Esta vertente é mais importante na prospecção mineral por permitir, potencialmente, o uso de imagens de sensoriamento remoto e não exigir, neste caso, importantes conhecimentos de botânica do geólogo responsável pela prospecção.

No Brasil, apesar de suas dimensões e das grandes áreas recobertas por florestas e cerrados, a geobotânica tem sido pouco utilizada, ainda que raros resultados publicados sejam positivos, com a associação de diferenças florísticas e fisionômicas descritas em Paradella et al. (1994), Paradella \& Vitorello (1995), Almeida Filho et al. (1996), Almeida Filho \& Vitorello (1997). Por outro lado Paradella \& Bruce (1990) e Amaral (1992) sugerem que a menor interação rocha/ solo/vegetação e a complexidade do ambiente das florestas tropicais dificultam, em princípio, a aplicação da geobotânica em trabalhos de prospecção mineral. Além destas dificuldades, segundo Paradella et al. (1994), a maior contribuição do substrato dá-se de forma indireta, com as variações fisionômicas sendo controladas principalmente pela topografia. Já a hipótese considerada por Condit et al. (2002) inviabiliza a geobotânica em florestas tropicais. Aqueles autores consideram estar a similaridade florística nestas florestas relacionada com o logaritmo da distância geográfica, implicando em mudanças graduais e ausência de contatos bruscos e mosaicos de vegetação, a qual manteria independência das tênues variações ambientais presentes naquele bioma. Isto, entretanto, não encontra respaldo em trabalhos baseados em extensivos dados de campo, como em Poulsen \& Balslev, (1991); Tuomisto et al. (1995); Riaza et al. (1998); Svenning (1999); Wright (2002); Schulze (2003) e Tuomisto et al. (2003), auto- res que demonstram que diferenças nos solos ao longo das florestas de terra firme, no oeste da Amazônia, são suficientemente importantes para gerar numerosos mosaicos floristicamente diferentes, com estruturas bem definidas e contrastes bruscos. Tuomisto et al. (2003), em transecto com $43 \mathrm{~km}$ de comprimento em Floresta de Terra-Firme no oeste da Amazônia, encontraram grande diversidade florística, com índices de Jaccard entre 0,01 e 0,71 , com valor médio de 0,27 . $O$ índice de Jaccard (Mueller-Dombois \& Ellenberg, 1974) permite quantificar a dissimilaridade entre coberturas vegetais e quando abaixo de 0,25 indica coberturas vegetais dissimilares. É assim evidente terem sido encontradas florestas completamente dissimilares. Como os autores daquele trabalho explicitam que a similaridade de padrões florestais exibe baixa correlação com a distância geográfica, a hipótese da aplicabilidade da geobotânica naquele bioma tem consistência.

A presença no Estado de São Paulo de grandes blocos florísticos associados a variações de altitude é consensual (Torres et al., 1997). Por outro lado não é questionada a correlação de variações fisionômicas e na composição em espécies com fatores abióticos de ordem bem mais restrita, tal como expõem Botrel et al. (2002) acerca da influência do solo e topografia. Assim Scudeller et al. (2001), analisando dados florísticos da Mata Atlântica, utilizam-se de uma amostragem de 19.677 indivíduos identificados em 771 espécies para dividir a Mata Atlântica em dois grandes grupos florísticos-estruturais: a Província Costeira e o Platô Atlântico, os quais, entretanto, possuem pequenos nichos florísticos. O padrão predominante é de distribuição restrita e alta variação local de espécies, indicando variabilidade de condições ambientais e a predominância de espécies em nichos ecológicos restritos. Concluem ainda haver poucas espécies generalistas, as quais apresentaram alta constância no estudo. Já Sztutman \& Rodrigues (2002) estudaram a florística, estrutura e fisionomia de três florestas do Parque Estadual da Campina do Encantado (PECE), no município de Pariqüera-Açu, São Paulo. As florestas não apresentam perturbação antrópica $\mathrm{e}$ são crescidas sobre turfeira pouco profunda (floresta turfosa rasa), sobre turfeira profunda (floresta turfosa profunda) e sobre solo firme e seco (floresta sobre morrote). Considerando que as três unidades estão sujeitas ao mesmo clima, as diferenças florísticas e estruturais devem-se essencialmente às características fisiográficas locais, como a topografia, solo e o substrato. Na floresta sobre morrote foram encontradas 112 espécies, com maior riqueza, em termos de famílias, de Myrtaceae seguida de Lauraceae, Leguminosae e Rubiaceae. Na floresta turfosa rasa foi encontrado em total de 46 espécies, com as duas famílias mais ricas sendo também Myrtaceae e Lauraceae. Já a floresta turfosa profunda apresentou apenas cinco espécies. Entre a floresta sobre morrote e a turfosa rasa ocorreram apenas 16 espécies em comum, implicando em índice de similaridade de Jaccard $\left(\mathrm{J}_{\mathrm{ac}}\right)$ de 0,109 para estas duas florestas. A comparação destas florestas com outras da região mostra alta similaridade da floresta sobre morrote com flores- 
ta sobre o embasamento cristalino em Pariqüera-Açu $\left(\mathrm{J}_{\mathrm{ac}}=0,460\right)$ e baixa com floresta sobre planície litorânea em Cananéia $\left(\mathrm{J}_{\mathrm{ac}}=0,103\right)$. Já a floresta turfosa rasa tem, ao contrário, similaridade alta com floresta sobre planície litorânea em Cananéia $\left(\mathrm{J}_{\mathrm{ac}}=0,328\right)$ e baixa com florestas sobre embasamento cristalino em PariqüeraAçu $\left(\mathrm{J}_{\mathrm{ac}}=0,088\right)$. As florestas do PECE demonstram de modo evidente que a proximidade geográfica não prepondera sobre as variações ambientais devidas ao meio físico.

Godoy (2001) estudou a estrutura e a composição de Mata Atlântica secundária sobre calcários e filitos no Alto Ribeira, Estado de São Paulo. Dividiu seu estudo em florestas com períodos de abandono após uso agrícola de 15 anos (inicial), de 25 anos (médio) e de pelo menos 40 anos (avançado). Sobre os calcários ocorreram 129 espécies e apenas 99 sobre os filitos. Do total, 68 espécies cresceram exclusivamente sobre calcários e 38 sobre filitos, com 61 comuns às duas formações geológicas, revelando similaridade $\left(\mathrm{J}_{\mathrm{ac}}=0,37\right)$. Entretanto, ao se calcular aquele índice separadamente nos intervalos de tempo de abandono, o valor cai para em torno de 0,20 nas áreas de período mais longo, abaixo, portanto, do limite de similaridade florística $(0,25)$, mesmo tratando-se de dois litotipos de larga ocorrência na região. Segundo o autor, a principal causa para estas dissimilaridades foi o solo, destacando-se os menores teores de alumínio e a maior fertilidade dos solos sobre calcários. E como causa secundária pode ser apontada a geomorfologia, parâmetro também dependente da geologia.

A pesquisa de que ora se apresentam os resultados procura demonstrar como um fragmento de Mata Atlântica montana secundária em avançado estágio de regeneração pode apresentar diferentes comunidades vegetais devidas à presença de rochas alteradas hidrotermalmente, numa situação em que as variáveis independentes à geologia pouco mudam. Uma comunidade vegetal refere-se ao conjunto de espécies que ocorre em um determinado local e ao arranjo destas espécies no espaço, sendo caracterizada florística e fisionômicamente. Observe-se que o fragmento florestal estudado apresenta forte dependência tanto florística como fisionômica com a presença de alteração hidrotermal, considerando que possui o mesmo histórico de regeneração há pelo menos vinte e cinco anos e possivelmente mais de 50 anos, o que caracteriza florestas em estágio secundário tardio de regeneração.

GEOLOGIA DA ÁREA DE ESTUDO A área de estudo tem seu centro nas coordenadas $23^{\circ} 17^{\prime} 12^{\prime \prime} \mathrm{S}$ e $46^{\circ} 22^{\prime} 20^{\prime \prime} \mathrm{W}$ e localiza-se a cerca de $40 \mathrm{~km}$ da cidade de São Paulo (Fig. 1).

Geomorfologicamente insere-se na serra do Itaberaba, em altitudes em torno de $900 \mathrm{~m}$. As rochas da região pertencem ao Grupo Serra do Itaberaba (Juliani et al., 1986; Juliani, 1993), de idade mesoproterozóica (Juliani et al., 2000), dividido em três formações, nomeadas, do topo para a base como Formação Pirucaia, Formação Nhanguçu e Formação Morro da Pedra Preta.

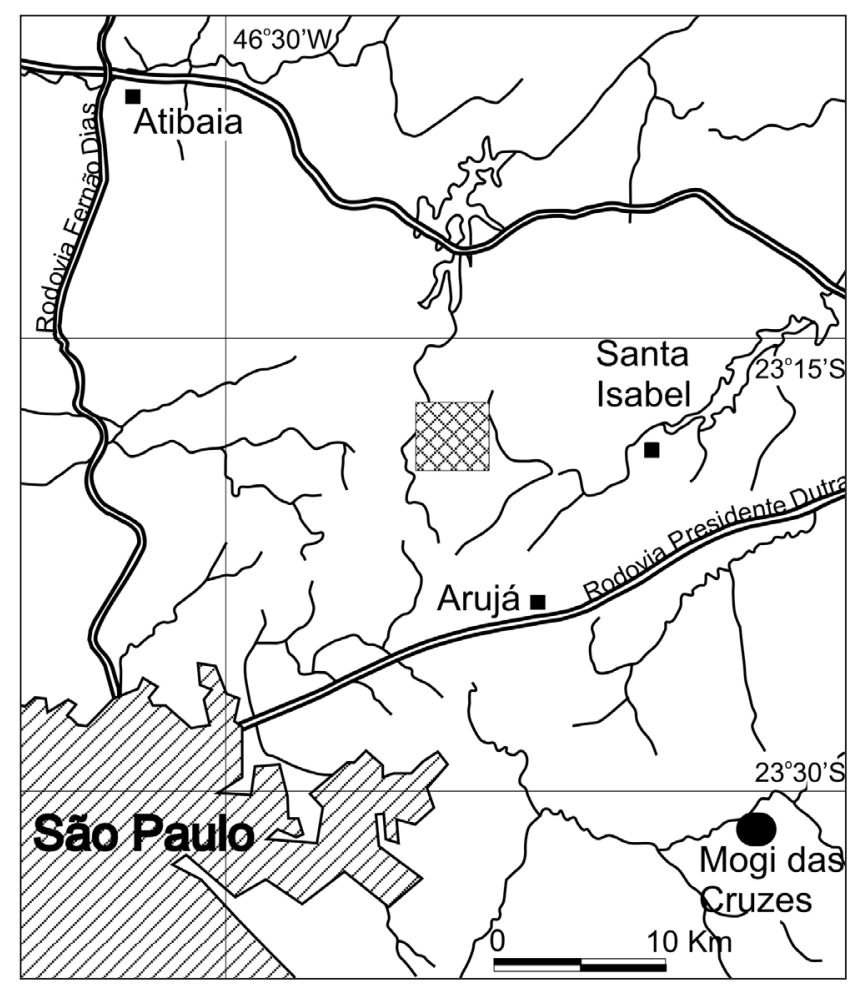

Figura 1 - Localização da área de estudo.

Esta última corresponde a uma seqüência vulcano-sedimentar metamorfisada em grau médio composta, em essência, por derrames básicos subaquáticos de filiação $\mathrm{N}$-MORB, xistos diversos, rochas vulcanoclásticas e cálcio-silicáticas, BIFs do tipo Algoma e pequenas intrusões de metaandesito e metariodacito. Durante a intrusão de andesitos e riodacitos desenvolveram-se sistemas hidrotermais, responsáveis pela presença de uma extensa zona de alteração clorítica e de mineralizações de ouro (Juliani et al., 1992; Beljavskis et al., 1993; Pérez-Aguilar et al., 2005). O evento de alteração clorítica afetou em diferentes intensidades rochas básicas a ácidas, mas principalmente intermediárias (Fig. 2), predominando, nestas últimas, andesitos basálticos $\mathrm{e}$ andesitos, os quais possuem uma composição próxima à das rochas básicas. Como conseqüência disto pode ser caracterizada nos produtos metamórficos uma gradação completa de litotipos incluindo rochas incipientemente alteradas, as da zona de transição, as menos intensamente alteradas e, finalmente, as intensamente alteradas (Pérez- Aguilar, 1996; Pérez-Aguilar, 2001; Pérez-Aguilar et al., 2005).

Os produtos metamórficos desta zona de alteração clorítica podem ser reconhecidos pela presença de rochas variavelmente enriquecidas pelos anfibólios magnesianos antofilita e/ou cummingtonita e/ou gedrita. As rochas incipientemente alteradas podem ser identificadas pela presença de pequenas quantidades de cummingtonita. Nas rochas da zona de transição coexistem tipicamente dois ou mais anfibólios metamórficos (magnesiohornblenda, tschermakita, antofilita, cummingtonita ou gedrita). As rochas menos intensamente alteradas caracterizam-se pela substituição de 


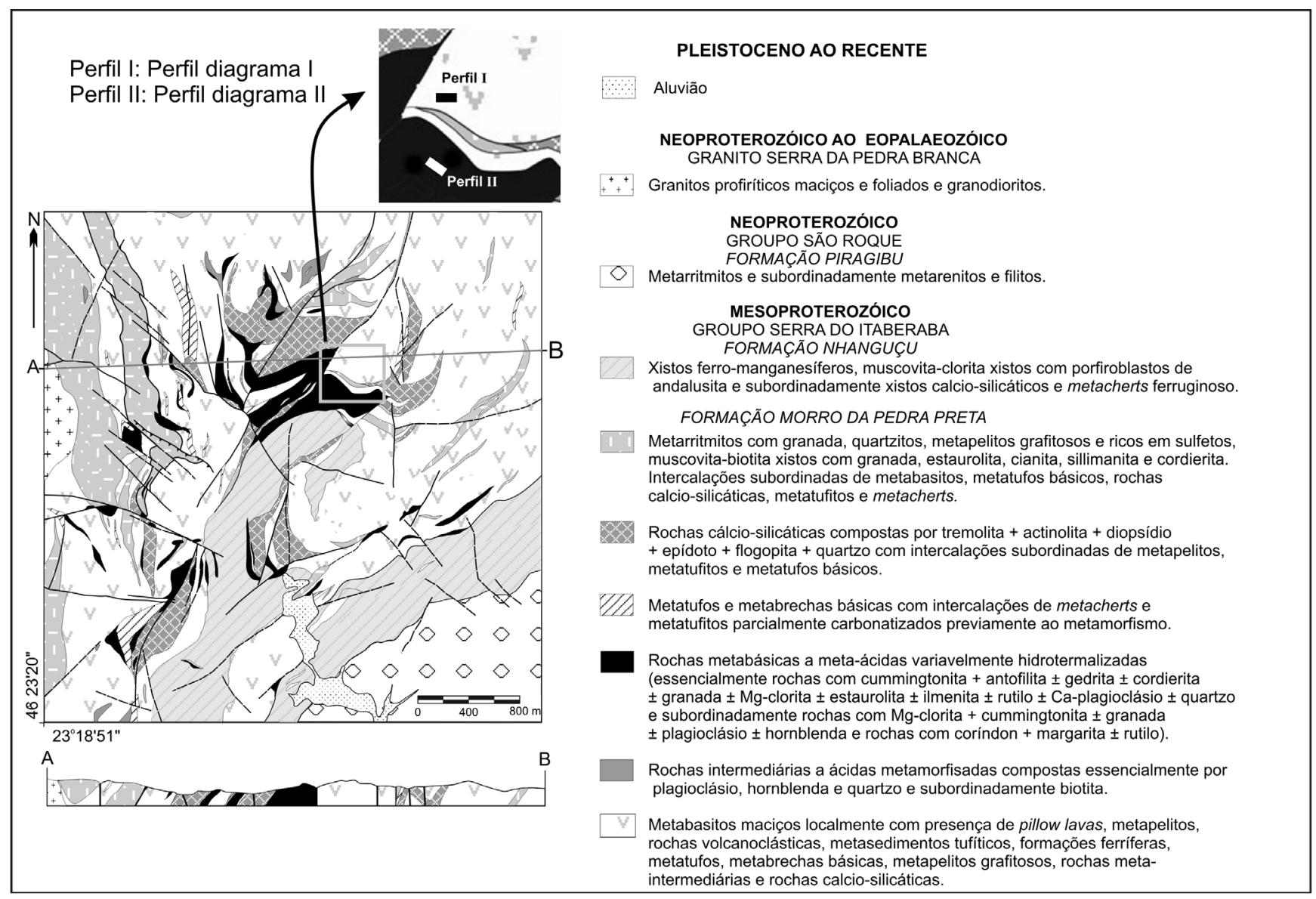

Figura 2 - Mapa geológico da área de estudo (modificado de Pérez-Aguilar, 1996).

toda a hornblenda por cummingtonita, podendo ser distinguidas duas zonas petrográficas, uma sem presença de granada (zona petrográfica $1, \mathrm{ZP} 1$ ) e outra com presença deste último mineral (zona petrográfica 2, ZP2). Finalmente, as rochas intensamente alteradas caracterizam-se por possuir arranjos radiados de anfibólio(s) magnesiano(s) e poiquiloblastos de granada e/ou cordierita centimétricos. Estas rochas serão referidas doravante como rochas com cummingtonita/antofilita, granada e cordierita, uma vez que predominam rochas intensamente alteradas onde coexistem cummingtonita e antofilita. (Pérez Aguilar et al., 2005).

Em campo podem ser reconhecidos também os produtos metamórficos de antigos canais de percolação de fluidos assim como feições de dissolução do protolito devido à passagem dos fluidos, sendo caracteristicamente observados restos do mesmo dentro dos litotipos alterados hidrotermalmente bem como gradações centimétricas a métricas mostrando desde rochas incipientemente alteradas até intensamente alteradas (Fig. 3), feições também observadas ao microscópio.

As mineralizações auríferas nesta região foram estudadas por Juliani (1993), Beljavskis et al., (1993; 1999) e Garda et al., (2002). As mineralizações supergênicas, detectadas em aluviões, coluviões, eluviões e saprólitos foram intensamente lavradas no período colonial. Juliani (1993), Beljavskis et al., (1993; 1999) e Garda et al., (2002) caracterizaram na Formação Mor- ro da Pedra Preta a presença de mineralizações de $\mathrm{Au}$, tanto do tipo singenético como epigenético. A mineralização singenética é observada em horizonte estratigráfico bem definido, ocorrendo na interface entre a seqüência vulcano-sedimentar da Formação Morro da Pedra Preta e os metapelitos ferro-manganesíferos sobrepostos, os quais foram incluídos por Juliani (1993) na Formação Nanguçu. Este tipo de mineralização está principalmente associado a rochas metaintermediárias de origem ígnea e metavulcanoclástica e a metacherts e turmalinitos, correspondendo estas duas últimas rochas a metaexalitos (produto metamórfico de rochas formadas por exalações vulcânicas). Mineralizações de Au singenético também podem estar presentes tanto em metapelitos grafitosos e/ou ricos em sulfetos como nas formações ferríferas. A granulação do ouro singenético é muito fina, não sendo possível a sua identificação ótica, estando caracteristicamente associado a sulfetos (principalmente pirrotita e pirita e, secundariamente, calcopirita) que por vezes alcançam mais de $10 \%$ do volume da rocha e tendem a concentrar-se em lâminas ou bandas paralelas a $\mathrm{S}_{0} / \mathrm{S}_{2}$. Os sulfetos, neste contexto, são também o produto de uma atividade vulcanoexalativa. Os teores em ouro variam de décimos de ppm a mais de 13 ppm. Além dos metaexalitos (metacherts e turmalinitos), também caracteristicamente associados à mineralização de ouro singenética, encontram-se as rochas com cummingtonita/antofilita, granada e cor- 


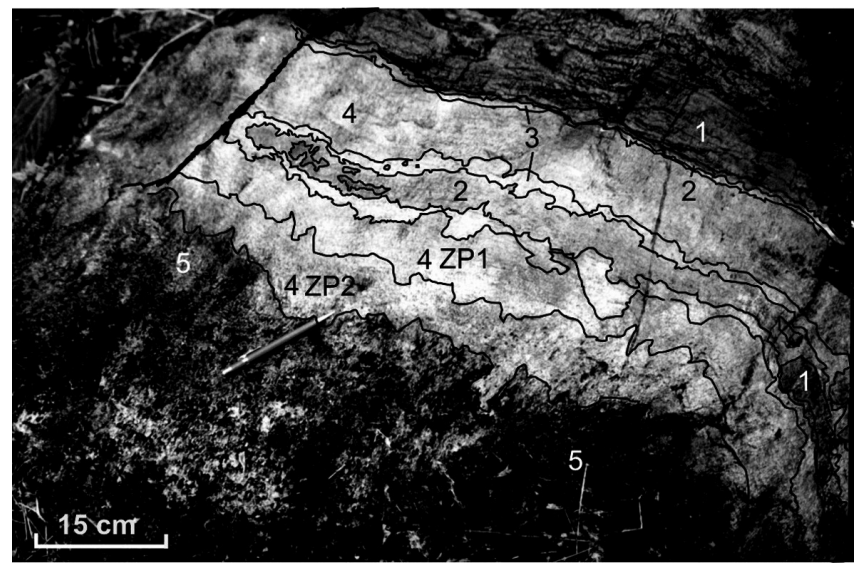

Figura 3 - Afloramento de rochas metavulcanoclásticas intermediárias alteradas hidrotermalmente mostrando a gradação entre rochas incipientemente alteradas até intensamente alteradas. (1) Rochas incipientemente alteradas, (2) rochas da zona de transição onde predomina horblenda sobre cummingtonita e onde foram preservados restos do protolito, (3) rochas da zona de transição onde predomina cummingtonita sobre hornblenda, (4 ZP1) rochas moderadamente alteradas sem presença de granada, (4ZP2) rochas moderadamente alteradas com presença de granada e (5) rochas intensamente alteradas. As linhas representam os limites entre os diferentes litotipos.

dierita, que correspondem, como acima explicado, ao produto metamórfico de uma extensa zona de alteração clorítica. A associação ouro-rocha intermediária-zona de alteração clorítica-exalito-sulfeto mostra que o sistema hidrotermal responsável pela gênese da zona de alteração clorítica esteve associado à mesma atividade vulcano-exalativa responsável pela formação dos exalitos e pela mineralização de ouro singenética.

A mineralização de ouro epigenética está essencialmente representada por remobilizações de ouro encontradas em veios de quartzo, estando o ouro associado principalmente a pirita e pirrotita, com teores variando entre 0,11 e 25,6 ppm. Muito embora os teores em ouro não sejam elevados, pontualmente são verificados até $40 \mathrm{~g} / \mathrm{t}$ (Beljavskis et al., 1993).

MATERIAL E MÉtOdOS A área de estudo foi selecionada pela presença de fragmentos de Mata Atlântica secundária em estágio tardio de regeneração que se desenvolveram tanto sobre rochas não alteradas (incluindo rochas metaintermediárias, metabásicas e diversos tipos de metapelitos) e rochas básicas e intermediárias alteradas de forma diferenciada. Como base geológica foi utilizado o mapa geológico de PerezAguilar (1996), como apresentado na figura 2.

Depois de caminhadas de reconhecimento, para selecionar porções com cobertura vegetal sem evidências de ação antrópica recente e considerando a geologia local, foram demarcadas e estudadas 17 parcelas exploratórias de $5 \times 5 \mathrm{~m}$ e dois perfis-diagrama de $4 \mathrm{x}$ $30 \mathrm{~m}$ (para localização, ver figura 2). As parcelas abar- caram diversos tipos litológicos, mas sua localização, dentro das subáreas selecionadas como descrito acima, foi sempre aleatória para evitar distorções subjetivas. Foram abrangidos tanto metabasitos, rochas metaintermediárias e metapelitos não alterados hidrotermalmente como metabasitos e rochas metaintermediárias afetadas de forma diferenciada pelo processo de alteração clorítica, incluindo rochas intensamente alteradas. Nestas parcelas foi coletado material vegetal de indivíduos arbóreos com diâmetro do caule à altura do peito (DAP) acima de $15 \mathrm{~cm}$, bem como das plantas dos estratos arbustivo e herbáceo, para posterior identificação das espécies. Foram ainda coletadas amostras de solo a $15 \mathrm{~cm}$ de profundidade em cada parcela, para avaliar as relações entre a presença de alteração hidrotermal e os principais parâmetros químicos e de $\mathrm{pH}$ dos solos. As amostras de solo foram encaminhadas para o Instituto Agronômico de Campinas, em Campinas, São Paulo, para análise de $\mathrm{pH}, \mathrm{P}, \mathrm{K}, \mathrm{Ca}, \mathrm{Mg}, \mathrm{B}, \mathrm{Cu}, \mathrm{Fe}, \mathrm{Mn}$, $\mathrm{Zn}, \mathrm{H}+\mathrm{Al}$ (alumínio reativo), matéria orgânica (M.O.), soma de bases (S.B.), capacidade de troca catiônica (CTC) e saturação em bases (V). Foram utilizados os métodos analíticos padrões do "sistema IAC de análise de solo" e os resultados de análises seguem o Sistema Internacional de Unidades.

$\mathrm{Na}$ escolha da localização dos perfis-diagrama foram delimitadas duas parcelas com o mínimo de variáveis, ou seja, com similares condições de declividade, de direção de vertente, altitude e estádio sucessional da floresta e ambas sobre protolitos semelhantes, mas apenas uma com presença de intensa alteração hidrotermal. Assim foram definidos e estudados dois perfisdiagrama de $4 \times 30 \mathrm{~m}$, distantes cerca de $150 \mathrm{~m}$ entre si, um sobre metabasitos sem alteração hidrotermal (perfil I) e outro sobre metaintermediárias e metabasitos intensamente alterados, com cummingtonita/antofilita, granada e cordierita (perfil II). Considerando que ambos os perfis foram delimitados próximos ao divisor de águas e em suave declividade, os solos têm pequeno ou nulo transporte e as variações na cobertura vegetal são atribuídas essencialmente às alterações físico-químicas produzidas no solo pela presença ou ausência de alteração hidrotermal. A área de cada perfil foi delimitada com marcações metro a metro, permitindo determinar a posição de cada exemplar arbóreo de DAP acima de 15 $\mathrm{cm}$, tendo sido anotada sua altura e diâmetro de copa e coletado material botânico para a identificação posterior das plantas, incluindo as espécies herbáceas e arbustivas. Simultaneamente à coleta foram desenhados os perfis-diagrama, auxiliando na observação da fisionomia das matas.

Quanto ao estágio sucessional, as espécies foram classificadas em pioneiras, aquelas cujo curto ciclo de vida é dependente de luz direta; em secundárias iniciais, aquelas que exigem grandes clareiras ao seu estabelecimento e desenvolvimento; em secundárias tardias, as que se estabelecem em clareiras pequenas e cujo ciclo de vida é superior a 50 anos; em espécies de sub-mata, aquelas que se estabelecem e desenvolvem todo o ciclo de vida no interior da floresta, sendo om- 
brófilas, e clímáxicas, as que são tolerantes à sombra nas fases jovens de desenvolvimento e que têm ciclos de vida muito longos.

Já quanto ao hábito de crescimento, estão identificadas em espécies arbóreas as espécies lenhosas que apresentam fuste distinto; em arbustivas, aquelas lenhosas com ramificações desde o nível do solo; em herbáceas, as plantas sem estruturas lenhosas, e em lianas, aquelas que dependem de outras plantas como suporte ao seu estabelecimento.

Para quantificar a similaridade florística adotou-se o Índice de Jaccard, comumente utilizado para analisar a similaridade entre dois conjuntos de espécies, considerando as espécies que são exclusivas de cada parcela e as que estão presentes em ambas. Quando o índice resulta superior a 0,25 , indica dissimilaridade florística.

O índice é calculado a partir da expressão:

$$
\mathrm{J}_{\mathrm{ac}}=\mathrm{a} /(\mathrm{a}+\mathrm{b}+\mathrm{c}) \text { sendo: }
$$

$\mathrm{J}_{\mathrm{ac}}=$ índice de similaridade;

$\mathbf{a}=\mathrm{n}^{\mathrm{o}}$ de espécies em comum às duas florestas;

$\mathbf{b}=\mathrm{n}^{\mathrm{o}}$ de espécies exclusivas da floresta 1 ;

$\mathbf{c}=\mathrm{n}^{\mathrm{o}}$ de espécies exclusivas da floresta 2.

RESULTADOS OBTIDOS Foram coletadas 97 espécies nas parcelas e perfis (Tab. 1) distribuídas em um total de 40 famílias. A família com maior riqueza foi Rubiaceae, com 13 espécies (13,7\%), seguida de Sapindaceae, Myrtaceae e Melastomataceae, respectivamente com nove, oito e sete espécies. O conjunto de espécies amostradas apresenta ampla distribuição e tem sido identificado em diversos trabalhos efetuados no domínio da floresta ombrófila densa Atlântica no sudeste do Brasil, não havendo espécies indicadoras de características distintivas.

Nas parcelas foram descritas 78 espécies, das quais 41 arbóreas com DAP maior que $15 \mathrm{~cm}$, distribuídas em uma média de quatro espécies arbóreas nas parcelas localizadas sobre rochas com presença de alteração hidrotermal e de 4,6 espécies nas parcelas sobre terrenos sem alteração hidrotermal significativa. Não foi identificada a correlação de espécies com a presença de alteração, exceto a clara correlação de grupos de Calathea cylindrica com acentuado gigantismo. Esta planta, comum no domínio da floresta ombrófila densa Atlântica e popularmente conhecida como Calatéia, é encontrada sistematicamente com perto do dobro de sua altura normal no solo desenvolvido sobre rochas com cummingtonita/antofilita, granada e cordierita. As espécies arbóreas mais comumente encontradas foram Aspidosperma olivaceum, Sloanea guianensis e Sloanea monosperma, denotando avançado estádio de sucessão, embora houvesse a presença freqüente de árvores pioneiras como Tibouchina pulchra. Os resultados das análises de solos obtidos nas parcelas estão na tabela 2 .

Nos dois perfis-diagrama foram descritas 49 espécies das quais 28 com hábito arbóreo e 21 correspondendo a plantas arbustivas, herbáceas e lianas, distribuídas em 28 famílias. Do total de famílias, 10 ocorrem exclusivamente no perfil 1 (sobre rochas sem alteração) - Apocynaceae, Arecaceae, Bignoniaceae, Commelinaceae, Euphorbiaceae, Icacinaceae, Lauraceae, Maranthaceae, Menispermaceae e Ulmaceae - e sete exclusivamente no perfil 2 (sobre rochas com intensa alteração hidrotermal) - Asteraceae, Cecropiaceae, Chrysobalanaceae, Cyperaceae, Rosaceae, Simaroubaceae e Styracaceae. Finalmente, há 11 de ocorrência comum aos dois perfis: Clusivaceae, Leguminosae, Melastomaceae, Meliaceae, Monimiaceae, Myrtaceae, Nyctaginaceae, Piperaceae, Poaceae, Rubiaceae e Sapindaceae. Dos 50 indivíduos de espécies de hábito arbóreo encontrados nos perfis há 31 , ou $62,0 \%$, no perfil 1 e 19, ou 38,0\%, no perfil 2 (Tab. 3). Dos 27 indivíduos de espécies arbustivas, herbáceas e lianas amostradas nos perfis, há $18(66,7 \%)$ no perfil 1 e nove no perfil 2 $(33,3 \%)$ (Tab. 4).

Foram coletados 48 indivíduos de 32 espécies no perfil 1, destacando-se as famílias Rubiaceae e $\mathrm{Sa}$ pindaceae, com seis espécies cada uma. Das espécies coletadas há duas pioneiras ou $6,3 \%$, oito secundárias iniciais $(25,0 \%)$, sete secundárias tardias $(21,9 \%), 12$ de sub-mata $(37,5 \%)$ e três climáxicas $(9,4 \%)$ ou $68,8 \%$ de tardias (secundárias tardias, climáxicas e de submata (Fig. 4A). No perfil 2, sobre rochas intensamente alteradas com cummingtonita/antofilita, granada e cordierita, foram coletados 28 indivíduos de 20 espécies e destaca-se a família Rubiaceae, com três espécies. Das espécies presentes, quatro ou $20,0 \%$ são pioneiras, duas ou $10 \%$ secundárias iniciais, três ou $15 \%$ secundárias tardias, sete ou $35 \%$ de sub-mata e quatro ou $20 \%$ climáxicas. Assim são sete espécies tardias que, somando-se às sete de sub-mata totalizam 14 , representando 70,0\% (Fig. 4B).

No total foram coletados 50 indivíduos das 28 espécies de hábito arbóreo. Destes, 29 indivíduos, distribuídos em 20 espécies, possuíam DAP $>15 \mathrm{~cm}$ (Tab. 3) e 21 indivíduos, distribuídos em 14 espécies, apresentavam DAP $<15 \mathrm{~cm}$. No perfil 1 foram coletados 31 indivíduos de 19 espécies de hábito arbóreo, das quais 15 com DAP $>15 \mathrm{~cm}$. Destas 15 espécies, 12 ou $80 \%$ são climáxicas, secundárias tardias e de sub mata e não há espécies pioneiras (Fig. 5A). No perfil 2 foram amostrados 19 indivíduos de 14 espécies de hábito arbóreo, pertencendo 11 indivíduos com DAP $>15 \mathrm{~cm}$ a 10 espécies, das quais 7 ou $70 \%$ são climáxicas, secundárias tardias e de sub-mata e 10\% são pioneiras (Fig. 5B).

No que tange às plantas arbustivas, lianas e herbáceas e excluindo os arbustos de espécies de hábito arbóreo, encontrou-se um total de 21 espécies, ocorrendo 15 no perfil 1 e 7 no perfil 2. Destas plantas há, no perfil 1 , duas $(13,3 \%)$ pioneiras, seis $(40,0 \%)$ secundárias iniciais, duas $(13,3 \%)$ secundárias tardias, seis de sub-mata $(40,0 \%)$ (Fig. 6A). No perfil 2 há três espécies pioneiras $(42,9 \%)$ e quatro espécies de sub-mata $(57,1 \%)$, não havendo espécies secundárias iniciais, secundárias tardias e climáxicas (Fig. 6B). Calathea cylindrica, que 
Tabela 1 - Conjunto de espécies amostradas nos trabalhos de campo

\begin{tabular}{|c|c|c|}
\hline Abuta selloana & Garcinia gardneriana & Peltastes peltatum \\
\hline Alibertia myrcifolia & Guadua Angustifolia & Pera glabrata \\
\hline Allophyllus petiolulatus & Guapira opposita & Picramnia parvifolia \\
\hline Allophylus edulis & Hirtela hebeclada & Piper cernuum \\
\hline Alternanthera sp. & Inga marginata & Piper gaudichaudianum \\
\hline Amaioua guianensis & Inga sessilis & Piptocarpha axillaris \\
\hline Amaioua meridionalis & Julocroton fuscecens & Posoqueria latifolia \\
\hline Anemia sp. & Leandra áurea & Prunus myrtifolia \\
\hline Aspidosperma olivaceum & Leandra mosenii & Psychotria malaneoides \\
\hline Bactris setosa & Leandra sp. 2 & Psychotria mapoureoides \\
\hline Bauhinia forficata & Licania octandra & Psychotria sessilis \\
\hline Bathysa meridionalis & Macfadyena unguis-cati & Psychotria suterella \\
\hline Cabralea canjerana & Maprounea guianensis & Psychotria vellosiana \\
\hline Calatea cylindrica & Matayba elaeagnoides & Rapanea cf. guianensis \\
\hline Cecropia glazioui & Merostachys scandens & Rapanea umbellata \\
\hline Celtis iguanae & Miconia cinnamomifolia & Rhynchospora aurea \\
\hline Cestrum schlechdentalii & Mollinedia schottiana & Rhynchospora corymbosa \\
\hline Chletra scabra & Myrceugenia myrcioides & Rudgea gardeneoides \\
\hline Citronella megaphylla & Myrcia cf. pubipetala & Rudgea jasminoides \\
\hline Clusia sp. & Myrcia rostrata & Serjania sp. \\
\hline Colanthelia mecrostachya & Myrciaria floribunda & Sloanea guianensis \\
\hline Commelina diffusa & Myrciaria myrcioides & Sloanea monosperma \\
\hline Croton floribundus & Nectandra mollis & Solanum sp. \\
\hline Cryptocarya moschata & Ocotea aciphylla & Styrax leprosum \\
\hline Cupania emarginata & Ocotea puberula & Swartzia acutifolia \\
\hline Cupania oblongifolia & Ocotea silvestris & Syagrus sp. \\
\hline Dalbergia brasiliensis & Olyra glaberrima & Tabebuia avellanedae \\
\hline Dichorisandra thyrsiflora & Ottonia martiana & Tapirira cf. marchandii \\
\hline Dioscorea $s p$ & Palicourea marcgravii & Tapirira guianensis \\
\hline Ecclinusa aff. ramiflora & Passiflora sp. & Thelypteris dentata \\
\hline Eugenia cerasiflora & Paullinia carpopoda & Tibouchina pulchra \\
\hline \multirow[t]{2}{*}{ Eugenia sulcata } & Paullinia seminuda & Tovomitopsis paniculata \\
\hline & Paullinia trigonia & \\
\hline
\end{tabular}

foi reconhecida apresentando gigantismo em terrenos com alteração hidrotermal, não foi encontrada dentro dos limites estabelecidos para o perfil 2.

Comparando o conjunto de 49 espécies encontradas nos dois perfis, foram encontradas 27 espécies exclusivas no perfil 1 e 15 no perfil 2 , com sete espécies comuns a ambos os perfis. Entre as 28 espécies de hábito arbóreo, 13 ocorrem exclusivamente no perfil 1, 9 no perfil 2 e seis em ambos os perfis. Já entre as espécies arbustivas, herbáceas e lianas, das 21 espécies amostradas, 14 são exclusivas ao perfil florestal $1 \mathrm{e}$ seis ao perfil florestal 2, com apenas uma espécie $(4,8 \%)$ ocorrendo em ambos os perfis. Calculando-se o Índice de Jaccard, encontra-se 0,14 para o conjunto de espécies encontradas, 0,21 para as espécies arbóreas e 0,05 para as espécies arbustivas, herbáceas e lianas.

Há uma estrutura mais complexa e desenvolvida no trecho de floresta representado no primeiro perfildiagrama, com árvores de até 18 metros, maior densidade da vegetação e estrutura da floresta mais com- plexa, com diversas formas de crescimento, incluindo maior biomassa e muitas lianas (Fig. 7A). Neste trecho de floresta salientam-se as espécies tardias e climáxicas Allophyllus edulis, Aspidosperma olivaceum, Cabralea canjerana, Cryptocarya moschata e Eugenia cerasifolia, além das espécies de sub-mata Bathysa meridionalis, Cupania oblongifolia, Mollinedia schottiana e Psychotria suterella. Das etapas iniciais da sucessão, ressalta-se Croton floribundus.

O segmento de floresta encontrado no perfildiagrama 2 é menos complexo do que o anterior. Tratase de um trecho de floresta com árvores de até $13 \mathrm{~m}$ de altura, espaçadas entre si, com estrutura relativamente simples e pequena quantidade de lianas e plantas arbustivas em seu interior, indicativas de uma sub-mata empobrecida em relação ao trecho de floresta indicado no perfil anterior (Fig. 7B). Ressaltam-se entre as espécies tardias e climáxicas Allophyllus petiolulatus, Licania octandra e Swartzia acutifolia, entre as espécies de sub-mata Bathysa meridionalis e Mollinedia schot- 
Tabela 2 - Resultado de análises de solos coletados nas parcelas exploratórias para MO (matéria orgânica), pH (acidez ativa), $H+A l$ (acidez potencial), S.B. (soma de bases), CTC (capacidade de troca de cátions), $V$ (saturação por bases), macronutrientes ( $P, K, C a$ e $M g$ ) e micronutrientes ( $\mathrm{B}, \mathrm{Cu}, \mathrm{Fe}, \mathrm{Mn}$ e $\mathrm{Zn})$.

\begin{tabular}{l|c|c}
\hline & $\begin{array}{c}\text { Rochas } \\
\text { alteradas } \\
\text { média }(\mathrm{n}=7)\end{array}$ & $\begin{array}{c}\text { Rochas não } \\
\text { alteradas } \\
\text { média }(\mathrm{n}=10)\end{array}$ \\
\hline $\mathrm{MO}\left(\mathrm{g} / \mathrm{dm}^{3}\right)$ & $26,33 \pm 7,71$ & $35,27 \pm 7,54$ \\
\hline $\mathrm{pH}(\mathrm{KCl})$ & $3,93 \pm 0,08$ & $3,88 \pm 0,12$ \\
\hline $\mathrm{P}\left(\mathrm{mg} / \mathrm{dm}^{3}\right)$ & $3,12 \pm 1,88$ & $5,55 \pm 2,78$ \\
\hline $\mathrm{K}\left(\mathrm{mmol}_{\mathrm{c}} / \mathrm{dm}^{3}\right)$ & $0,50 \pm 0,24$ & $0,79 \pm 0,16$ \\
\hline $\mathrm{Ca}\left(\mathrm{mmol}_{\mathrm{c}} / \mathrm{dm}^{3}\right)$ & $1,00 \pm 0,00$ & $1,66 \pm 1,42$ \\
\hline $\left.\mathrm{Mg}\left(\mathrm{mmol}_{\mathrm{c}} / \mathrm{dm}^{3}\right)\right)$ & $1,00 \pm 0,00$ & $1,36 \pm 0,48$ \\
\hline $\mathrm{H}+\mathrm{Al}\left(\mathrm{mmol}_{\mathrm{c}} / \mathrm{dm}^{3}\right)$ & $95,00 \pm 28,17$ & $127,55 \pm 21,64$ \\
\hline $\mathrm{S} . \mathrm{B} .\left(\mathrm{mmol} / \mathrm{dm}^{3}\right)$ & $2,52 \pm 0,21$ & $3,82 \pm 1,73$ \\
\hline $\mathrm{CTC}\left(\mathrm{mmol} / \mathrm{dm}^{3}\right)$ & $97,67 \pm 28,16$ & $131,40 \pm 20,92$ \\
\hline $\mathrm{V}(\%)$ & $2,78 \pm 0,66$ & $3,06 \pm 1,51$ \\
\hline $\mathrm{B}\left(\mathrm{mg} / \mathrm{dm}^{3}\right)$ & $0,35 \pm 0,10$ & $0,43 \pm 0,11$ \\
\hline $\mathrm{Cu}\left(\mathrm{mg} / \mathrm{dm}^{3}\right)$ & $1,88 \pm 0,86$ & $2,96 \pm 1,46$ \\
\hline $\mathrm{Fe}\left(\mathrm{mg} / \mathrm{dm}^{3}\right)$ & $45,33 \pm 15,53$ & $61,91 \pm 44,99$ \\
\hline $\mathrm{Mn}\left(\mathrm{mg} / \mathrm{dm}^{3}\right)$ & $15,27 \pm 11,52$ & $14,52 \pm 11,02$ \\
\hline $\mathrm{Zn}\left(\mathrm{mg} / \mathrm{dm}^{3}\right)$ & $0,67 \pm 0,26$ & $1,17 \pm 0,59$ \\
\hline
\end{tabular}

tiana, além das espécies arbóreas pioneiras Cecropia glazioui e Piptocarpha axillaris. Finalmente, a altura média do dossel é de aproximadamente $14 \mathrm{~m}$ no perfil 1 e de $8 \mathrm{~m}$ no perfil 2, onde o dossel é claramente mais aberto, corroborando com a presença mais freqüente de espécies pioneiras, como mostrado na figura 6 .

DISCUSSÃO DOS RESULTADOS Os dados obtidos nas parcelas exploratórias, localizadas sobre diferentes condições de topografia, orientações de vertente e litotipos, incluindo rochas não alteradas (metaintermediárias, metabasitos e metapelitos diversos) e rochas metabásicas e metaintermediárias alteradas de forma diferenciada, não fornecem tendências claras, salvo a presença de uma menor diversidade de espécies de hábito arbóreo com $\mathrm{DAP}>15 \mathrm{~cm}$ na presença de alteração hidrotermal. É importante considerar que as características da cobertura vegetal dependem de outras variáveis, além das causadas pelo substrato geológico e pelo solo. Florinsky \& Kuryakova (1996) e Rowan et al. (2000) demonstram como a topografia intervém nas coberturas vegetais de forma independente ao substrato rochoso, ao clima e à pedogênese. Já Bognar et al.(1999) expõem que apenas a variação no horário da iluminação solar direta (matutina, vespertina) impõe severas diferenças nas coberturas vegetais, em função de variações diurnas da interação da radiação eletromagnética com os fitocromos, constituindo a orientação da vertente uma variável independente em relação à variável dos solos. Desta forma a ausência de tendências encontrada

Tabela 3 -Espécies arbóreas com DAP>15 cm coletadas nos perfis florestais, com identificação de seu estádio de sucessão. Os algarismos identificam o $n^{\circ}$ de indivíduos de cada espécie nestes perfis. Perfil 1 sobre metabasitos sem alteração hidrotermal; Perfil 2 sobre rochas semelhantes afetadas por intensa alteração hidrotermal prémetamórfica.

\begin{tabular}{|c|c|c|c|c|}
\hline Família & Gênero espécie & Estádio de sucessão & Perfil 1 & Perfil 2 \\
\hline Apocynaceae & Aspidosperma olivaceum & SI & 1 & - \\
\hline Asteraceae & Piptocarpha axillaris & SI & - & 1 \\
\hline Cecropiaceae & Cecropia glaziou & PI & - & 1 \\
\hline Chrysobalanaceae & Licania octandra & $\mathrm{CL}$ & - & 2 \\
\hline Clusiaceae & Tovomitopsis paniculata & ST & 1 & 1 \\
\hline Euphorbiaceae & Croton floribundus & SI & 1 & - \\
\hline Lauraceae & $\begin{array}{l}\text { Cryptocarya moschata } \\
\text { Nectandra mollis }\end{array}$ & $\begin{array}{l}\mathrm{CL} \\
\mathrm{ST} \\
\end{array}$ & $\begin{array}{l}1 \\
1 \\
\end{array}$ & - \\
\hline Leguminosae & Swartzia acutifolia & $\mathrm{CL}$ & - & 1 \\
\hline Meliaceae & Cabralea canjerana & ST & 3 & - \\
\hline Monimiaceae & Mollinedia schottiana & $\mathrm{SM}$ & 1 & 1 \\
\hline Myrtaceae & Eugenia cerasifolia & $\mathrm{CL}$ & 1 & - \\
\hline Nyctaginaceae & Guapira opposita & ST & 2 & 1 \\
\hline Rosaceae & Prunus myrtifolia & SI & - & 1 \\
\hline Rubiaceae & $\begin{array}{l}\text { Amaioua guianensis } \\
\text { Bathysa meridionalis } \\
\text { Psychotria suterelal }\end{array}$ & $\begin{array}{c}\text { SI } \\
\text { SM } \\
\text { SM }\end{array}$ & $\begin{array}{l}1 \\
1 \\
1\end{array}$ & $\begin{array}{l}- \\
1 \\
-\end{array}$ \\
\hline Sapindaceae & $\begin{array}{l}\text { Allophyllus petiolulatus } \\
\text { Cupania emarginata } \\
\text { Cupania oblongifolia }\end{array}$ & $\begin{array}{l}\text { SM } \\
\text { ST } \\
\text { SM }\end{array}$ & $\begin{array}{l}1 \\
1 \\
1\end{array}$ & $\begin{array}{l}1 \\
- \\
-\end{array}$ \\
\hline
\end{tabular}

Legenda:

PI:

Pioneira;

SI:

Secundária Inicial;

$S T$ :

Secundária Tardia;

$S M$ :

Sub-Bosque;

$C L$ :

Climáxica. 
Tabela 4 - Espécies arbustivas, herbáceas e lianas e espécies de hábito arbóreo com DAP $<15 \mathrm{~cm}$. Hábito de crescimento: $A V$-árvores; $B U$ - arbusto; HE - herbáceo; LI - liana. Os algarismos das duas colunas à direita se referem ao número de individuos em cada perfil. PI = Pioneira; $S I=$ Secundária Inicial; $S T=$ Secundária Tardia; $S M=$ Sub-Bosque; $C L=$ Climáxica. Perfil 1 sobre metabasitos sem alteração hidrotermal; Perfil 2 sobre rochas semelhantes afetadas por intensa alteração hidrotermal pré-metamórfica.

\begin{tabular}{|c|c|c|c|c|c|}
\hline Família & Gênero espécie & $\begin{array}{l}\text { Hábito de cr } \\
\text { Estádio de }\end{array}$ & $\begin{array}{l}\text { nto/ } \\
\text { ão }\end{array}$ & Perfil 1 & Perfil 2 \\
\hline Apocynaceae & $\begin{array}{l}\text { Aspidosperma olivaceum } \\
\text { Peltastes peltatum }\end{array}$ & $\begin{array}{l}\mathrm{AV} \\
\mathrm{LI}\end{array}$ & $\begin{array}{l}\text { SI } \\
\text { SI }\end{array}$ & $\begin{array}{l}1 \\
1 \\
\end{array}$ & - \\
\hline Arecaceae & Bactris setosa & PA & SM & 1 & - \\
\hline Bignoniaceae & Macfadyena unguis-cati & LI & ST & 1 & - \\
\hline Clusiaceae & Tovomitopsis paniculata & $\mathrm{AV}$ & ST & 2 & - \\
\hline Commelinaceae & Dichorisandra thyrsiflora & $\mathrm{HE}$ & SM & 1 & - \\
\hline Cyperaceae & Rhynchospora corymbosa & $\mathrm{HE}$ & PI & - & 1 \\
\hline Icacinaceae & Citronella megaphylla & $\mathrm{AV}$ & ST & 1 & - \\
\hline Leguminosae & $\begin{array}{l}\text { Bauhinia forficata } \\
\text { Inga sessilis }\end{array}$ & $\begin{array}{l}\text { LI } \\
\mathrm{AV}\end{array}$ & $\begin{array}{l}\text { ST } \\
\text { CL }\end{array}$ & $\begin{array}{l}2 \\
-\end{array}$ & $\begin{array}{l}- \\
1\end{array}$ \\
\hline Maranthaceae & Calathea cylindrica & $\mathrm{HE}$ & SM & 1 & - \\
\hline Melastomataceae & $\begin{array}{l}\text { Leandra áurea } \\
\text { Leandra mosenii }\end{array}$ & $\begin{array}{l}\mathrm{BU} \\
\mathrm{BU}\end{array}$ & $\begin{array}{l}\text { PI } \\
\text { PI }\end{array}$ & $\begin{array}{l}1 \\
- \\
\end{array}$ & $\begin{array}{l}- \\
1 \\
\end{array}$ \\
\hline Meliaceae & Cabralea canjerana & AV & ST & - & 1 \\
\hline Menispermaceae & Abuta selloana & $\mathrm{AV}$ & ST & 1 & - \\
\hline Monimiaceae & Mollinedia schottiana & $\mathrm{AV}$ & SM & 2 & - \\
\hline Myrtaceae & $\begin{array}{l}\text { Eugenia sulcata } \\
\text { Myrcengenia myrcioides }\end{array}$ & $\begin{array}{l}\mathrm{AV} \\
\mathrm{AV}\end{array}$ & $\begin{array}{l}\mathrm{CL} \\
\mathrm{CL}\end{array}$ & $\begin{array}{l}- \\
1\end{array}$ & $\begin{array}{l}1 \\
-\end{array}$ \\
\hline Nyctaginaceae & Guapira opposita & AV & ST & - & 1 \\
\hline Piperaceae & $\begin{array}{l}\text { Ottonia martiana } \\
\text { Piper cernuum } \\
\text { Piper gaudichaudianum }\end{array}$ & $\begin{array}{l}\mathrm{BU} \\
\mathrm{BU} \\
\mathrm{BU}\end{array}$ & $\begin{array}{l}\text { SM } \\
\text { SM } \\
\text { SM }\end{array}$ & $\begin{array}{l}2 \\
- \\
1\end{array}$ & $\begin{array}{l}- \\
1 \\
-\end{array}$ \\
\hline Poaceae & $\begin{array}{l}\text { Colanthelia macrostachya } \\
\text { Merostachys scandens } \\
\text { Olyra glaberrima }\end{array}$ & $\begin{array}{l}\text { BU } \\
\text { BU } \\
\text { BU }\end{array}$ & $\begin{array}{l}\text { PI } \\
\text { PI } \\
\text { SM }\end{array}$ & $\begin{array}{l}- \\
1 \\
-\end{array}$ & $\begin{array}{l}1 \\
- \\
1\end{array}$ \\
\hline Rubiaceae & $\begin{array}{l}\text { Alibertia myrcifolia } \\
\text { Psychotria mapoureoides } \\
\text { Psychotria suterella } \\
\text { Psychotria vellosiana }\end{array}$ & $\begin{array}{l}\text { AV } \\
\text { BU } \\
\text { AV } \\
\text { BU }\end{array}$ & $\begin{array}{l}\text { SM } \\
\text { SM } \\
\text { SM } \\
\text { SM }\end{array}$ & $\begin{array}{l}1 \\
- \\
4 \\
2\end{array}$ & $\begin{array}{l}- \\
1 \\
- \\
3\end{array}$ \\
\hline Sapindaceae & $\begin{array}{l}\text { Paullinia carpopoda } \\
\text { Paullinia seminuda } \\
\text { Paullinia trigonia }\end{array}$ & $\begin{array}{l}\text { LI } \\
\text { LI } \\
\text { LI }\end{array}$ & $\begin{array}{l}\text { SI } \\
\text { SI } \\
\text { SI }\end{array}$ & $\begin{array}{l}1 \\
1 \\
1\end{array}$ & $\begin{array}{l}- \\
- \\
-\end{array}$ \\
\hline Simaroubaceae & Picramnia parvifolia & $\mathrm{AV}$ & SM & - & 2 \\
\hline Styracaceae & Styrax leprosum & AV & $\mathrm{ST}$ & - & 2 \\
\hline Ulmaceae & Celtis iguanae & LI & SI & 1 & - \\
\hline
\end{tabular}

no conjunto de parcelas exploratórias pode dever-se à presença de um conjunto de variáveis independentes, ou parcialmente independentes, demasiado grande em relação à amostragem. As análises de solos da tabela 2 mostram que os gerados sobre rochas alteradas hidrotermalmente têm teores mais baixos em diversos macronutrientes $(\mathrm{P}, \mathrm{K}, \mathrm{Ca}, \mathrm{Mg})$ e micronutrientes $(\mathrm{B}, \mathrm{Cu}$, Fe e $\mathrm{Zn}$ ), bem como na soma de bases, na capacidade de troca de cátions e na presença de matéria orgânica. Há que se acrescentar ainda que tais solos são também menos espessos.

Já os perfis 1 e 2, por suas características topográficas e geológicas, compõem uma fonte de dados mais adequada para a discussão pretendida. Os resultados aí obtidos, em que pese serem áreas de dimensões mais restritas que o ideal, são consistentes, permitindo definir duas comunidades distintas, tanto quando analisadas em relação às espécies arbóreas com DAP $>15$ (informação de maior interesse numa aplicação de sensoriamento remoto) como no conjunto de lianas e plantas dos estratos arbustivo e herbáceo. A presença de alta porcentagem de espécies climáxicas, secundárias tardias e de sub-mata em ambos os perfis demonstra seu estádio de sucessão similar e avançado. Considerando que a floresta Atlântica montana é rica em espécies de Myrtaceae, Lauraceae, Melastomataceae e Rubiaceae 


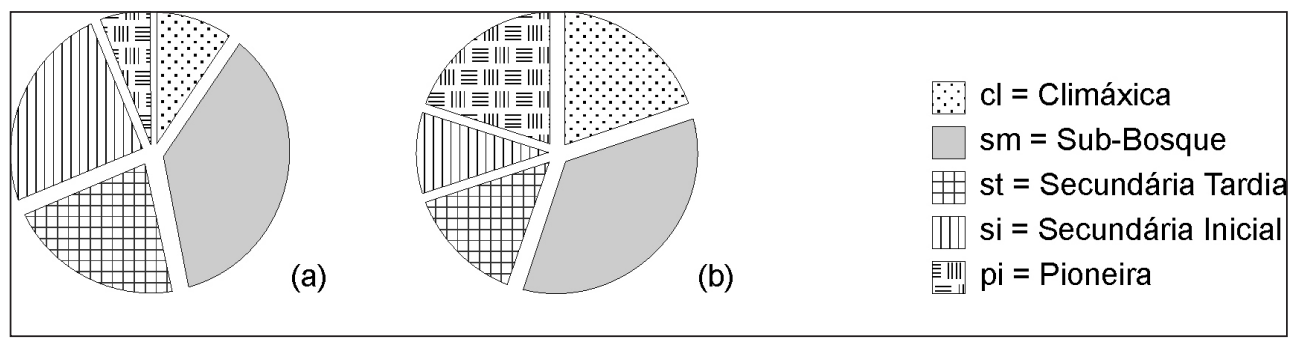

Figura 4 - Distribuição do total de espécies coletadas no perfil florestal sobre os tipos de rochas: (a) sem alteração hidrotermal (A) (Perfil I); (b) com alteração (B) (Perfil II), classificadas de acordo com seu estádio sucessional, segundo os tipos relacionados na legenda. Observar similaridade na participação de espécies de avançado grau de sucessão ou tardias (climáxicas, sub-mata e secundárias tardias) e participação significativa de espécies pioneiras apenas no perfil sobre rochas alteradas.

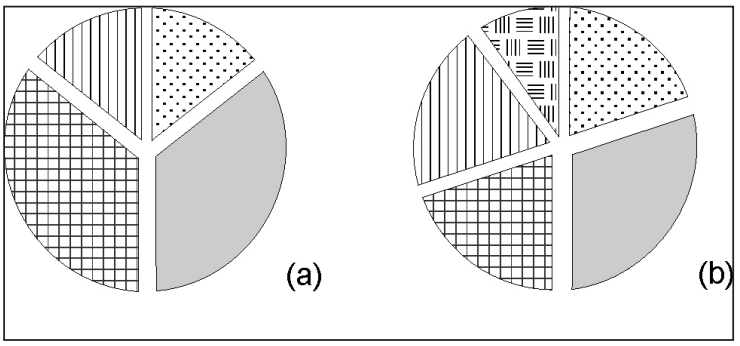

Figura 5 - Distribuição de espécies arbóreas coletadas nos perfis florestais, classificadas de acordo com seu estádio sucessional. Em (a) espécies arboreas com DAP maior que $15 \mathrm{~cm}$ (perfil I); em (b), com DAP maior que $15 \mathrm{~cm}$ (perfil II). Observar distribuição similar de espécies climáxicas e de sub-mata e presença de pioneiras apenas no perfil II. Ver legenda na fig. 4.

(Tabarelli \& Mantovani, 1999) a distribuição das famílias descritas neste estudo não foge do comumente encontrado neste tipo de floresta, já que as famílias mais ricas em espécies são as mesmas, excetuando-se Sapindaceae.

As fisionomias visualizadas nos perfis da Figura 7 mostram, sobre substrato sem alteração hidrotermal, uma floresta mais desenvolvida, com estrutura complexa em seu sub-bosque, incluindo lianas. Comparando-se as áreas com e sem alteração, a biodiversidade é maior nesta última, tanto em espécies de hábito arbóreo (19 versus 15) como espécies arbustivas, herbáceas e lianas (15 versus 7). Comparando-se com o encontrado por Rowan et al. (2000) em estudo sobre florestas crescidas em áreas com e sem alteração hidrotermal nos estados de Virgínia e Geórgia, nos EUA, verifica-se a mesma tendência entre as relações de biodiversidade: 1,9 vezes mais espécies arbóreas/parcela sobre rochas não alteradas e 1,5 de espécies arbustivas e herbáceas nos EUA e, respectivamente, 1,3 e 2,1 na serra do Itaberaba.

Destaca-se também a porcentagem de espécies pioneiras no total das plantas coletadas: $5,9 \%(2 / 34)$ no perfil I, sem alteração hidrotermal, e 18,2\% (4/ 22)

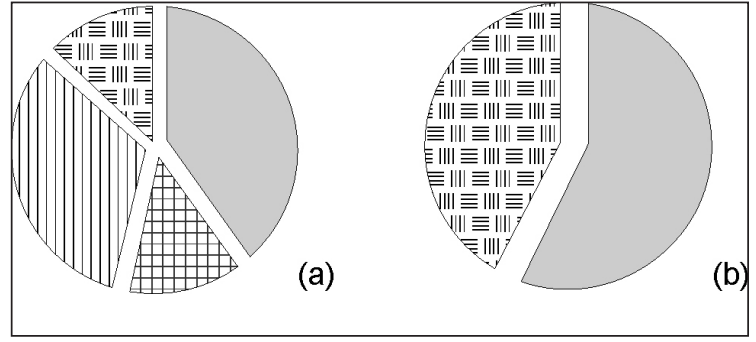

Figura 6 - Distribuição das espécies de plantas arbustivas, herbáceas e lianas coletadas nos perfis florestais, classificadas de acordo com seu estádio sucessional em PI = Pioneira; $S I=S e$ cundária Inicial; $S T=$ Secundária Tardia $; S M=$ Sub-Bosque; $C L=$ Climáxica. Em (a) espécies ocorrentes no Perfil I e, em (b), no perfil II. Observar a importância de espécies pioneiras no perfil sobre rochas com alteração hidrotermal. Ver legenda na Figura 4.

no perfil II. As espécies pioneiras não são tolerantes ao sombreamento e sua presença mais dominante neste último perfil deve-se ao dossel mais aberto, característica também reportada por Rowan et al. (2000) nas parcelas sobre rochas com alteração hidrotermal.

A distribuição das famílias de plantas nos perfis é notável. Foram encontradas 28 famílias, 10 exclusivas do perfil 1, 7 do perfil 2 e $11(39,3 \%)$ comuns a ambos. Em termos de espécies, o índice de Jaccard de 0,14 para o conjunto de plantas amostradas denota significativa dissimilaridade, menos importante entre as espécies arbóreas $(0,21)$, mas muito acentuada para as espécies arbustivas, herbáceas e lianas $\left(\mathrm{J}_{\mathrm{ac}} \mathrm{de} 0,05\right)$.

Dois aspectos tendem a diminuir artificialmente os valores obtidos para o Índice de Jaccard encontrados. As dimensões das áreas amostradas são pequenas e há uma elevada diversidade beta, típica de regiões muito ricas em espécies, como no domínio da floresta ombrófila densa Atlântica. Mas não há dúvidas de que os resultados indicam nítidas variações estruturais e florísticas entre as áreas, salientando-se, no perfil 2, 

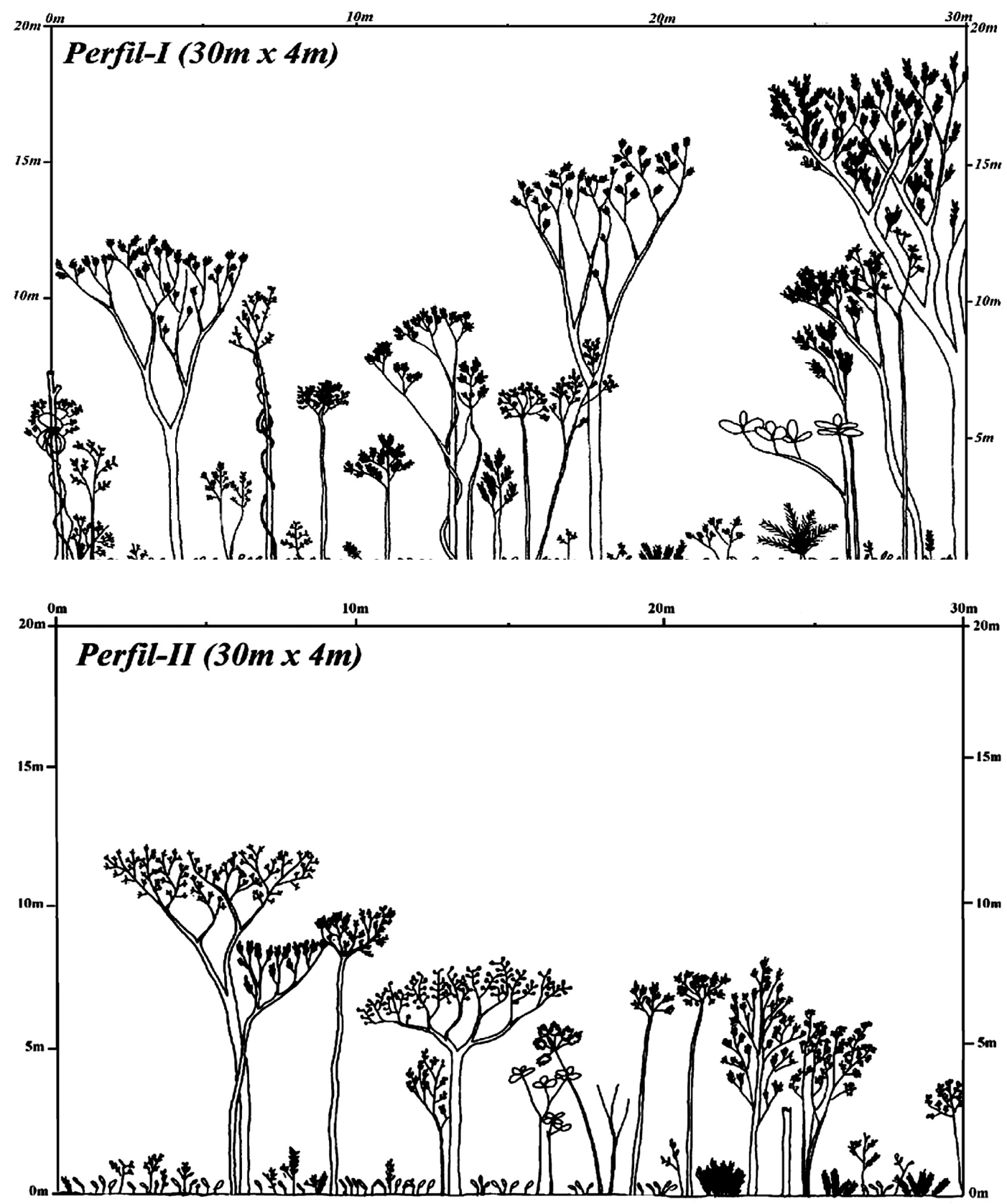

Figura 7 - Perfil esquemático dos perfis florestais I, sobre rochas sem alteração hidrotermal e II, sobre rochas intensamente alteradas, com cummingtonita/antofilita, granada e cordierita. Observar a floresta mais alta, a estrutura mais complexa e o dossel mais fechado no perfil $I$.

a presença de famílias que comumente têm espécies pioneiras, como Asteraceae e Cecropiaceae. Estas diferenças provêm, essencialmente, da presença de alteração hidrotermal na formação do substrato rochoso e seu reflexo nos solos, já que os demais aspectos que poderiam influir nas coberturas vegetais dos perfis são praticamente idênticos.

CONCLUSÕES Na floresta ombrófila densa Atlântica montana obtiveram-se diferenças florísticas e estruturais bem definidas como resposta à presença ou ausência no substrato de rochas alteradas hidrotermalmente (alteração clorítica), às quais estão associadas geneticamente as mineralizações de ouro. As espécies encontradas nos dois perfis analisados, embora de ocorrência comum na floresta ombrófila densa Atlântica, caracterizam a existência de duas comunidades florestais diferentes. Comparativamente os dois perfis apresentam variação florística que, quantificada pelo índice de Jaccard, revela alta dissimilaridade, denotando uma floresta de menor biodiversidade sobre as rochas com alteração hidrotermal. As diferenças nas fisionomias foram também marcantes, com uma estrutura mais complexa e dossel mais alto e fechado na ausência de alteração hidrotermal no substrato. As causas para as dissimilaridades encontradas estão nos solos residuais, mais pobres 
e mais rasos quando desenvolvidos a partir de rochas alteradas hidrotermalmente.

Estes dados são de valia para futuros estudos de prospecção mineral, por dois motivos. Primeiramente demonstra não apenas a presença, mas quantifica a forte intensidade de alterações florísticas e fisionômicas em floresta tropical crescida sobre substrato com alteração hidrotermal. Em segundo lugar, demonstrando haver associação de zona de alteração hidrotermal com uma comunidade florística e fisionomicamente dissimilar ao padrão regional, espera-se que tal associação seja replicacada na presença de condições ambientalmente semelhantes. Uma vez que os corpos filonianos mineralizados em ouro são em geral pequenos, sua identificação por anomalias geobotânicas é praticamente impossível. Entretanto as zonas de alteração hidrotermal associadas às mineralizações de ouro e de metais de base são comumente extensas, o que pode provocar alterações na flora em áreas maiores. Tais áreas podem ser identificadas por estudos geobotânicos e, potencialmente, por sensoriamento remoto, o que pode se constituir em uma importante ferramenta nos trabalhos de prospecção mineral em áreas pouco conhecidas, de difícil acesso e com densa cobertura vegetal a impedir a obtenção, por sensoriamento remoto, de respostas espectrais de origem mineral.

Embora a floresta ombrófila densa Atlântica ocupe hoje uma área muito reduzida, o aqui observado poderá ocorrer em outros biomas de alta biodiversidade e grande extensão e muitas vezes de difícil acesso, como a Floresta Amazônica. Ainda que o sensoriamento remoto não tenha sido abordado, três aspectos encontrados nesta pesquisa poderão ser interessantes em aplicações de sensoriamento remoto na detecção de nichos diferenciados: (i) diferentes assembléias de espécies arbóreas poderão ter respostas espectrais também diferentes; (ii) dosséis mais abertos sobre rochas alteradas podem influenciar o albedo e (iii) a maior porcentagem de plantas pioneiras sobre rochas alteradas deve implicar em maior reflectância em todo o espectro óptico, principalmente no infravermelho próximo onde a reflexão especular é sabidamente mais intensa.

Finalmente, sugere-se que estudos voltados à análise de semelhanças entre coberturas florestais sob condições edáficas e/ou geológicas diferentes devem priorizar áreas com semelhante orientação e declividade das vertentes, para não introduzir variáveis independentes aos solos.

Agradecimentos Os autores agradecem à Fapesp pelo financiamento da pesquisa (processo 98/06913-6R) e ao técnico Paulo César Souza, do Instituto de Biociências da Universidade de São Paulo, pelo inestimável auxílio em todas as campanhas de campo.

\section{Referências}

Almeida Filho R. \& Vitorello I. 1997. Remote sensing data integration in the definition of hydrotermally altered áreas in vegetated terrain, central Brazil. Int. J. Rem. Sens., 18:1835-1842.

Almeida Filho R., Vitorello I., Correia V.R.M. 1996. Use of Landsat Thematic Mapper imagery as mineral propecting tool in the Tin Province of Goiás, Brazil. Geocarto Intern,. 11:61-69.

Amaral G. 1992. Estudos geobotânicos no Vale do Ribeira com base em sensoriamento remoto. Boletim IG-USP. (Publicação Especial), 12:11-12.

Baker A.M.J., Brooks R.R. 1988. Botanical exploration for minerals in the humid tropics. J. Biogeography, 15:221-229.

Beljavskis P., Garda G.M., Juliani C. 1993. Características das mineralizações auríferas no Grupo Serra do Itaberaba, Guarulhos, SP. Rev. Inst Geol., 14:21-29.

Beljavskis P., Juliani C., Garda G.M., Bettencourt J.S., Xavier R.P. 1999. Overview of the gold mineralization in the metavolcanic-sedimentary sequence of the Serra do Itaberaba Group, São Paulo, Brazil. In: C.J. Standley (ed.) Mineral Deposits. Processes to Processing, 1, Balkema, Roterdam, p.151-153.

Bognar L.K., Hall A., Adam E., Thain S.C., Nagy F., Millar A.J. 1999. The circadian clock controls the expression pattern of the circadian input photoreceptor, phytochrome B. Proc. Nat. Acad. Sc., 96:14652-14657.

Botrel R.T., Oliveira Filho A.T., Rodrigues L.A., Curi N. 2002. Influência do solo e topografia sobre as variações da composição florística e estrutura da comunidade arbóreo-arbustiva de uma floresta estacional semidecidual em Ingaí, MG. Rev. Bras. Bot., 25:195-213.

Condit R., Pitman N., Leight E.G.JR, Chave J., Terborgh J., Foster R.B., Nuñes V.P., Aguilar S., Valencia R., Villa G., Muller-Landau H.C., Losos E., Hubbell S.P. 2002. Beta-diversity in tropical trees. Science, 295:666-669.

Florinsky I.V. \& Kuryakova G.A. 1996. Influence of topography on some vegetation cover properties. Catena, 27:123-141.

Garda G.M., Beljavskis P., Juliani C., Boyce A.J. 2002. Sulfur stable isotope signatures of the Morro da Pedra Preta Formation, Serra do Itaberaba Group, São Paulo State, Brazil. Geochimica Brasiliensis 16:79-97.

Godoy J.R.L. 2001. Estrutura e composição especifica da Mata Atlântica secundária de encosta sobre calcário e filito, no Parque Estadual Turístico do Alto Ribeira, Iporanga, SP. 2001. Dissertação de Mestrado, Instituto de Biociências, Univ. de São Paulo, 112p.

Juliani C. 1993. Geologia, petrogênese e aspectos metalogenéticos dos Grupos Serra do Itaberaba e São Roque na região das serras do Itaberaba e da Pedra Branca, NE da cidade de São Paulo, SP. Tese de Doutoramento, Instituto de Geociências, Universidade de São Paulo, 703p.

Juliani C., Beljavskis P., Schorscher H.D. 1986. Petrogênese do vulcanismo e aspectos metalogenéticos associados: Grupo Serra de Itaberaba na região do São Roque. In: SBG, Congr. Bras. Geol., 34, Anais, p. 730-743.

Juliani C., Hackspacher P.C., Dantas E.L., Fetter A.H. 2000. 
The mesoproterozoic volcano-sedimentary Serra do Itaberaba Group of the Central Ribeira Belt, São Paulo, Brazil: implications for the age of overlying São Roque Group. Rev. Bras. Geoc., 30:82-86.

Juliani C., Schorscher H.D., Pérez-Aguilar A., Beljavskis P. 1992. Cordierita-granada-cummingtonita anfibolitos no Grupo Serra do Itaberaba (SP): evidência de alterações hidrotermais-metassomáticas pré-metamórficas. In: Inst. Geoc. Univ. São Paulo, Jornadas Científicas, 2, Atas, Publicação Especial 12, p. 59-61.

Mueller-Dombois D. \& Ellenberg H. 1974.Aims and methods of vegetation ecology. New York, John Wiley \& Sons, $547 \mathrm{p}$.

Nagaraju A. \& Karimulla S. 2001.Geobotany and biogeochemistry of Gymnosporia Montana - a case study from Nellore Mica Belt, Andhra Pradesh. Environ. Geol., 41:167-173.

Paradella W.R. \& Bruce W.D. 1990. Geobotânica por sensosenso $\neg$ res remotos: uma revisão. R. Bras. Geoc. 19:425435.

Paradella W.R., Silva M.F.F. da, Rosa N.A., Kushigbor C.A. 1994. A geobotanical approach to the tropical rain forest environment of the Carajás Mineral Province (Amazon Region, Brazil), based on digital TM data and DEM data. Int. J. Rem. Sens. , 15:1633-1648.

Paradella W.R. \& Vitorello I. 1995. Geobotanical and soil spectral investigation in the Caatinga environment (Brazil) based on multitemporal remote sensing data. Can. J. Rem. Sens., 21:52-59.

Pérez-Aguilar A. 1996. Geologia, petrologia e gênese dos granada-cordierita-cummingtonita/antofilita anfibolitos e rochas associadas do Grupo Serra do Itaberaba, SP. Dissertação de Mestrado, Instituto de Geociências, Universidade de São Paulo, 148p.

Pérez-Aguilar A. 2001. Petrologia e litoquímica de rochas de paleossistemas hidrotermais oceânicos mesoproterozóicos da seqüência metavulcanossedimentar do Grupo Serra do Itaberaba, SP. Tese de doutoramento, Instituto de Geociências, Univ. de São Paulo, 196p.

Pérez-Aguilar A., Juliani C., Monteiro L.V.S., Fallick A.E., Bettencourt J.S. 2005. Stable isotopic constraints on Kuroko-type paleo-hydrothermal systems in the Mesoproterozoic Serra do Itaberaba Group, São Paulo State, Brazil. J. South Am. Earth Sc., 18:305-321.

Poulsen A.A \& Balslev H. 1991. Abundance and cover of ground herbs in a Amazonian rain forest. J. Veg Sc., 2:315-322.

Riaza M.L., Martinez-Torres R., Ramon-Lluch J., Alonso P. 1998. Heras Evolution of equatorial vegetation communities mapped using Thematic Mapper images through a geographical information system (Guinea. Equatorial Africa). Int. J. Rem. Sen., 19:43-54.
Rowan L.C., Crownley J.K., Schimidt R.G., Ager C.M., Mars J.C. 2000. Mapping hydrotermally altered rocks by analyzing hyperspectral image (AVIRIS) data of forested areas in the Southeastern United States. J. Geoch. Explor., 68:145-166.

Schulze M.D. 2003. Ecology and behavior of nine timber species in Pará, Brazil: links between species life history and forest management and conservation. Eberly, Tese de Doutoramento, Pennsylvania State University, 355p.

Scudeller V.V., Martins F.R., Shepherd G.J. 2001. Distribution and abundance of arboreal species in the atlantic ombrophilous dense forest in Southeastern Brazil. Plant Ecology, 152:185-199.

Svenning J.C. 1999.Microhabitat specialization in a speciesrich palm community in Amazonian Ecuador. J. Ecology, 87:55-65.

Sztutman M.E. \& Rodrigues R.R. 2002. O mosaico vegetacional numa área de floresta contínua da planície litorânea, Parque Estadual da Campina do Encantado, Pariquera-Açu, SP. Rev. Bras. Bot., 25:161-176.

Tabarelli M. \& Mantovani W. 1999. A riqueza de espécies arbóreas na floresta atlântica de encosta no estado de São Paulo (Brasil). Rev. Bras. Bot., 22:217-223.

Torres R. B., Martins F.R.L., Kinoshita S. 1997. Climate, soil, and tree flora relationship in forests in the state of São Paulo, southeastern Brazil. Rev. Bras. Bot., 20:41-49.

Tuomisto H., Poulsen A.D., Moran R.C. 1998. Edaphic distribution of some species of the fern genus Adiantun in Western Amazonian. Biotropica, 30:392-399.

Tuomisto H., Ruokolainen K., Aguilar M., Sarmiento A. 2003. Floristic patterns along a $43-\mathrm{km}$ long transect in an Amazon rain forest. Journal of Ecology, 91:743-756.

Tuomisto H., Ruokolainen K., Kalliola R., Linna A., Danjoy W., Rodriguez Z. 1995. Dissecting Amazonian biodiverbiodiversity. Science, 269:63-66.

Ustin S.L., Smith M.O., Jacquemoud S., Verstraete M.M, Govaerts Y. 1999. Geobotany: Vegetation Mapping for Earth Sciences. In: A.N.Rencz (ed.) Manual of Remote Sensing: Remote Sensing for the Earth Sciences. 3rd Edition, New York, John Wiley and Sons, vol. 3., Chapter 4, p. 189-248.

Wright S.J. 2002. Plant diversity in tropical forests: a review of mechanisms of species coexistence. Oecologia, 130:1-14.

Xu R. \& Ma Y. 2004. Remote sensing research in biogeochemistry of the Hetai gold deposit, Guandong Province, China. Int. J. Rem. Sen., 25:437-453.

Manuscrito AE-053/2006

Recebido em 30 de outubro 2006 Aceito em 26 de fevereiro de 2007 